Article

\title{
Electronic Structure and High Magnetic Properties of (Cr, Co)-codoped 4H-SiC Studied by First-Principle Calculations
}

\author{
Mengyu Zhang ${ }^{1}$, Jingtao Huang ${ }^{2}$, Xiao Liu ${ }^{3, *}$, Long Lin $^{2,4}$ and Hualong Tao ${ }^{5}$ \\ 1 Yellow River Conservancy Technical Institute, Kaifeng 475004, China; zmy3660@163.com \\ 2 Henan Key Laboratory of Materials on Deep-Earth Engineering, School of Materials Science and \\ Engineering, Henan Polytechnic University, Jiaozuo 454000, China; 211706020022@home.hpu.edu.cn (J.H.); \\ linlong@hpu.edu.cn (L.L.) \\ 3 School of Energy Science and Engineering, Henan Polytechnic University, Jiaozuo 454000, China \\ 4 School of Mathematics and Informatics, Henan Polytechnic University, Jiaozuo 454000, China \\ 5 Liaoning Key Materials Laboratory for Railway, School of Materials Science and Engineering, \\ Dalian Jiaotong University, Dalian 116028, China; Taohualong01@163.com \\ * Correspondence: liuxiao666_hpu@163.com
}

Received: 29 June 2020; Accepted: 20 July 2020 ; Published: 23 July 2020

check for updates

\begin{abstract}
The electronic structure and magnetic properties of $3 d$ transition metal $(\mathrm{Cr}, \mathrm{Co})$-codoped $4 \mathrm{H}-\mathrm{SiC}$ were studied by density functional theory within GGA methods. The results show that all doped magnetic atoms have high magnetic properties in both $\mathrm{Cr}$-doped and Co-doped $4 \mathrm{H}-\mathrm{SiC}$, resulting in the net magnetic moments of 3.03, $3.02 \mu_{B}$ for $\mathrm{Si}_{35} \mathrm{CrC}_{36}$ and $\mathrm{Si}_{35} \mathrm{CoC}_{36}$. The electronic density of states reaches the peak at Fermi level, which is beneficial to the electronic transitions, indicating that $\mathrm{Cr}$-doped $4 \mathrm{H}-\mathrm{SiC}$ is a semi-metallic material. In addition, the magnetic properties of $(\mathrm{Cr}, \mathrm{Co})$-codoped $4 \mathrm{H}-\mathrm{SiC}$ were also calculated. The results show that the $(\mathrm{Cr}, \mathrm{Co})$-codoped $4 \mathrm{H}-\mathrm{SiC}$ system has more stable ferromagnetic properties with $\Delta E_{F M}$ of $-244.3 \mathrm{meV}$, and we estimated $T_{C}$ of about $470.8 \mathrm{~K}$ for the $(\mathrm{Cr}, \mathrm{Co})$-codoped $4 \mathrm{H}-\mathrm{SiC}$ system. The $(\mathrm{Cr}, \mathrm{Co})$-codoped $4 \mathrm{H}-\mathrm{SiC}$ can be ferromagnetic through some mechanism based on hybridization between local Cr:3d, Co:3d and C:2p states. These interesting discoveries will help promote the use of excellent SiC-based nanomaterials in spintronics and multi-function nanodevices in the near future.
\end{abstract}

Keywords: dilute magnetic semiconductor; $3 d$ transition metal; magnetism; $4 \mathrm{H}-\mathrm{SiC}$; density functional theory

\section{Introduction}

Dilute magnetic semiconductors (DMSs) have stimulated extensive attention because of their important applications in spintronics [1-6]. In recent years, there have been many ways to prepare DMSs by doping transition metals (TM) atoms in semiconductors host [7-9]. SiC is a promising wide bandgap DMS host that has broad application prospects in high-temperature, high-power, high-frequency and high-thermal conductivity devices [10-13]. The coherent manipulation at the millisecond level of isolated electron spins within the double-vacancy defects of silicon carbide has also appeared in recent literature studies [14-16]. This research laid the foundation for the application of silicon carbide in the fields of quantum communication, nano-scale nuclear magnetic resonance, intracellular magnetic, electrical, and thermal field imaging. Compared with other polytypes, $4 \mathrm{H}-\mathrm{SiC}$ is an ideal DMS material because of its high electron mobility, electron saturation and drift speed. Because of its excellent properties, $4 \mathrm{H}-\mathrm{SiC}$ has been widely studied by theoretical and experimental researchers [17-19]. 
In the design of actual electronic equipment, defects and impurities are the most commonly used means to regulate electrical, magnetic, optical and other properties. As far as experiments are concerned, Song et al. [20] studied the magnetic properties of $6 \mathrm{H}-\mathrm{SiC}$ doped with $\mathrm{Mn}$ atoms. They found that both the doping concentration of $\mathrm{Mn}$ and the defects affected ferromagnetism. Wang et al. [21] synthesized Mn-doped SiC thin films and studied the structure and magnetic properties of Mn-doped SiC. Huang et al. [22] tested the magnetic properties of $\mathrm{Cr}$-doped 6H-SiC single crystal and observed the ferromagnetic properties of the sample at low temperature. The Curie apparent temperature is $69.8 \mathrm{~K}$. In addition, the electronic structure and magnetic properties of the transition metal-doped with $\mathrm{SiC}$ were studied. Ma et al. [23] studied the magnetic properties of TM (TM $=\mathrm{Cr}$, $\mathrm{Mn}, \mathrm{Fe}$ ) atom doped $6 \mathrm{H}-\mathrm{SiC}$. The results show that $\mathrm{Cr}$ - and $\mathrm{Mn}$-doped $6 \mathrm{H}-\mathrm{SiC}$ are semi-metallic ferromagnetic, $\mathrm{Co}-$ and $\mathrm{Ni}$-doped $6 \mathrm{H}-\mathrm{SiC}$ have almost no magnetic properties, and $\mathrm{Fe}$-doped $6 \mathrm{H}-\mathrm{SiC}$ is paramagnetic. Alazri et al. [24] studied the magnetism of $6 \mathrm{H}-\mathrm{SiC}$ doped with $\mathrm{Mn}$ atom. They found that $\mathrm{Mn}$ atoms have magnetic moments for the substitution of $\mathrm{Si}$ and C. Bouziane et al. [25] studied the magnetism of 3C-SiC doped with $\mathrm{Mn}$ atom. The results showed that replacing Si with Mn can enhance the magnetic properties. Luo et al. [26] investigated the magnetism of different non-magnetic metal dopants on the $2 \mathrm{D}-\mathrm{SiC}$ monolayer. The results show that, with the increase of $\mathrm{Mg}-\mathrm{Mg}$ distance, the interaction between the two $\mathrm{Mg}$ dopants tends to be magnetic coupling over a long distance, and the coupling comes from $p-d$ exchange.

With the DMSs, the coupling between local magnetic moments is an indispensable factor for inducing long-period spin ordering. For DMSs doped with a transition metal, the local magnetic moment is mainly provided by transition metal elements. The debate on ferromagnetic theory is primarily focused on the determination of local magnetic moment coupling media. It is shown that if the impurities have a limited local magnetic moment, it is possible to generate magnetism in the matrix material. Some related modeling work $[27,28]$ using first principles not only extends the scope of DFT methods for silicon-based systems containing transition metal atoms, but also demonstrates the feasibility of predictions made at the level of similar theoretical approaches. As far as we know, theoretical studies on the magnetic properties of SiC-base wide band-gap semiconductors doped with $\mathrm{Cr}$ and $\mathrm{Co}$ atoms are relatively rare. Using the first principle, the mechanism of local magnetic moment and ferromagnetic properties in $(\mathrm{Cr}, \mathrm{Co})$ co-doped $4 \mathrm{H}-\mathrm{SiC}$ was studied in this paper.

\section{Model and Computational Method}

The $3 \times 3 \times 1$ supercell model of $4 \mathrm{H}-\mathrm{SiC}$ with 72 atoms was shown in Figure 1 . The large supercells used in the calculations allow us to simulate the distribution of various dopants and their magnetic configurations. As shown in Figure 1, the $\mathrm{Cr}$ dopant is fixed at the position marked 0, the $\mathrm{Si}$ atom labeled 1-12 is the position substituted by the doped Co atom, and the silicon vacancy is labeled $V_{S i}$. Site 0 is selected as the position where the $\mathrm{Cr}$ atom is mono-doped and the Co atom is mono-doped. This work is carried out by using the first-principles calculation package Cambridge Sequential Total Energy Package (CASTEP) [29] based on the spin density functional theory (DFT) [30-32], and the Kohn-Sham equations were solved using the Perdew-Burke-Ernerhof GGA approximation [33]. We have considered both DFT $+\mathrm{U}$ and DFT calculations in the system for all configurations of $(\mathrm{Cr}$, Co)-codoped $4 \mathrm{H}-\mathrm{SiC}$, where the $\mathrm{U}$ value were selected as 3.0 and 2.5 for $\mathrm{Cr}$ and $\mathrm{Co}$ atoms $[34,35]$. The convergence criteria for the geometric structures, stability, electronic and magnetic properties of $4 \mathrm{H}-\mathrm{SiC}$ are as below, plane-wave energy cut-off is $400 \mathrm{eV}$, the Brillouin-zone integrations are performed with the special $2 \times 2 \times 2$ Monkhost and Pack k-points mesh. 


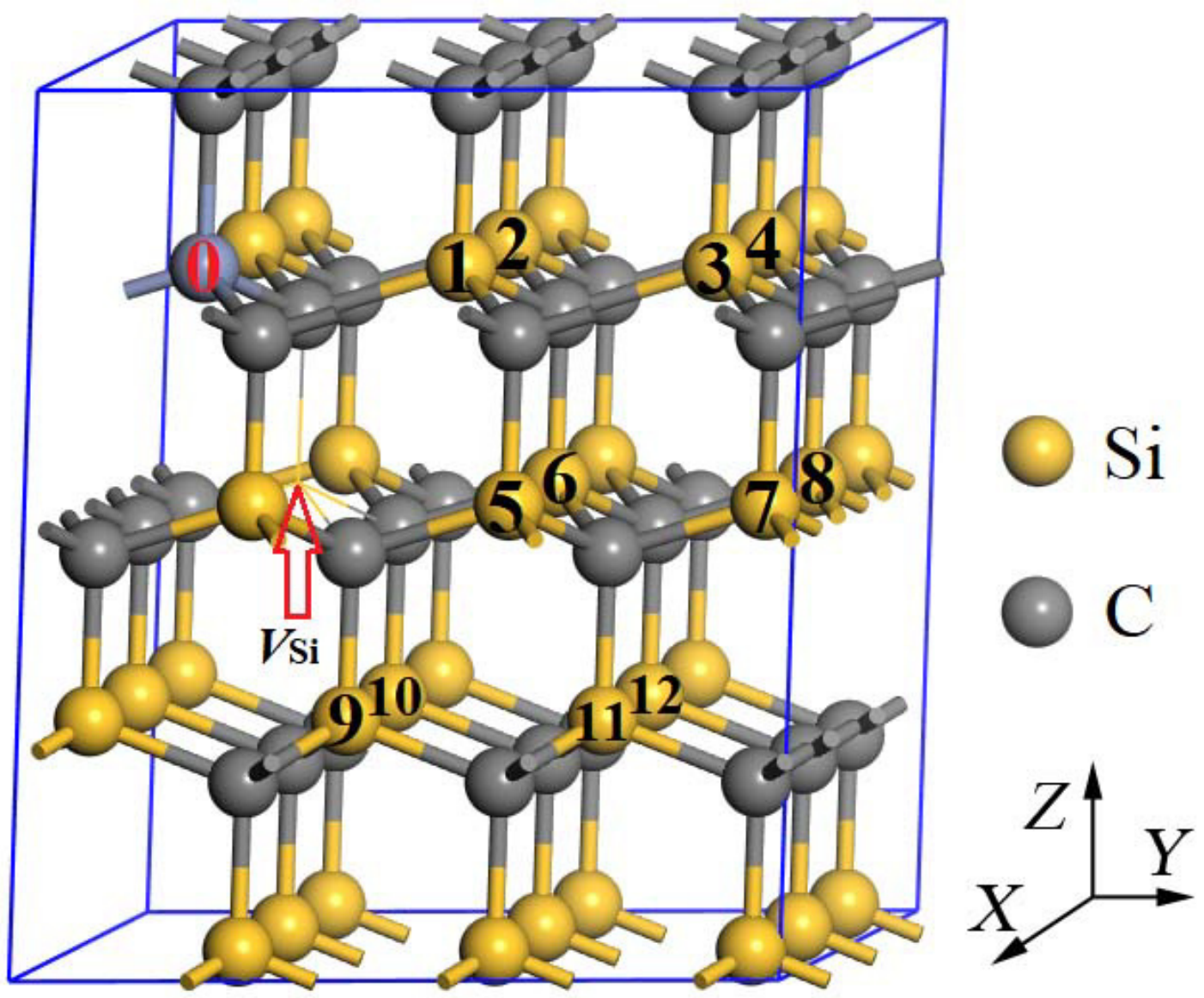

Figure 1. A $3 \times 3 \times 1$ supercell model of $4 \mathrm{H}-\mathrm{SiC}$ with 72 atoms. The $\mathrm{Cr}$ dopants is fixed at the position labeled 0 , the Si atoms labeled by 1-12 are the sites to bereplaced by the doped Co atoms. The silicon vacancy is labeled $V_{S i}$.

\section{Results and Discussion}

\section{1. $\mathrm{Cr}$ and Co-doped $4 \mathrm{H}-\mathrm{SiC}$}

We first considered a single $\mathrm{Cr}$-doped $4 \mathrm{H}-\mathrm{SiC}$ system, as shown in Figure 1, with a doping concentration of 2.78 at.\%. The hybrid state of $\mathrm{Cr}$ and $\mathrm{Si}$ after replacing a $\mathrm{Si}$ atom with a $\mathrm{Cr}$ atom in $3 \times 3 \times 1$ supercells was calculated. The results show that the maximum magnetic moment is $3.03 \mu_{B}$ due to the presence of $\mathrm{Cr}$ impurities in the $\mathrm{Si}$ site. Cr atoms play an important role in the generation of magnetic moments.

Hence one $\mathrm{Cr}$ contributes $2.79 \mu_{B}$ to the moment. The total and partial density of states (DOS) of $\mathrm{Cr}$-doped $4 \mathrm{H}-\mathrm{SiC}$ system were calculated, as shown in Figure 2, compared to the intrinsic $4 \mathrm{H}-\mathrm{SiC}$ system [36], we found that the total DOS after doping are asymmetrical. This is also an important reason why the system displays magnetism. It also can be seen from Figure 2a that the total DOS indicates that the $\mathrm{Cr}$-doped $4 \mathrm{H}-\mathrm{SiC}$ system is half metallic (i.e., spin-up (-down) states are available (not available) at the Fermi level, $E_{F}$ ). From Figure 2 we can see that the spin-down state is essentially idle, which is the same trend as most DMSs. To further investigate the electronic structure of Cr-doped $4 \mathrm{H}-\mathrm{SiC}$ system, we present the spin-dependent partial DOS of the $\mathrm{Cr}$, $\mathrm{Si}$ and $\mathrm{C}$ atoms for the $\mathrm{Si}_{35} \mathrm{CrC}_{36}$, which is listed in Figure $2 b-d$. It can be seen from Figure 2 that the total DOS near the Fermi level is mainly composed of the Cr:3d states and the C:2p states. There is a great exchange split between the majority spin bands and the minority spin bands of Cr:3d states. 


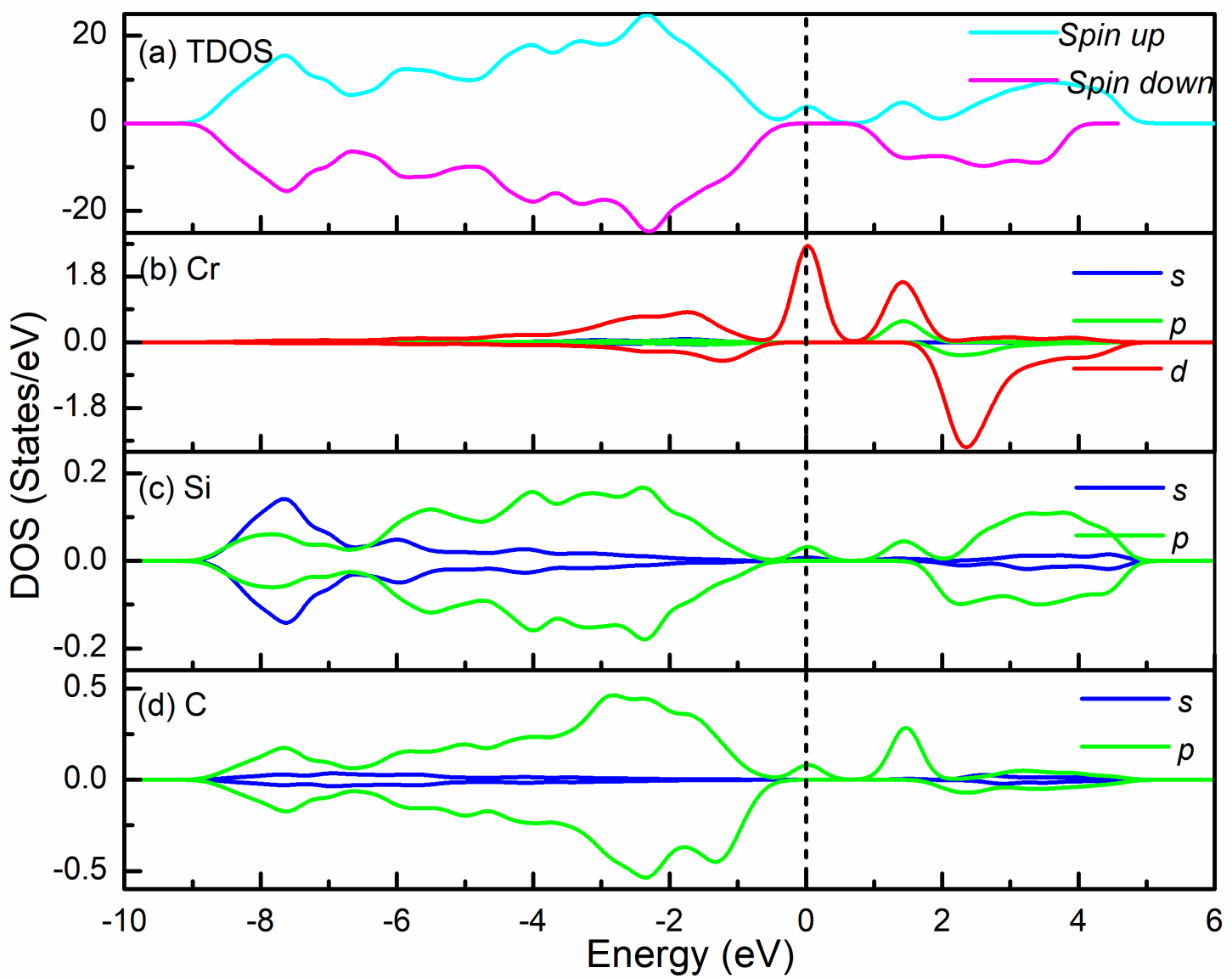

Figure 2. (a-d) The total and partial density of states (DOS) of Cr-doped $4 \mathrm{H}-\mathrm{SiC}$. The Fermi level is set to $0 \mathrm{eV}$.

Due to the local magnetic moment is the basis of ferromagnetic formation $[37,38]$, next, we choose $\mathrm{Co}$ atoms instead of $\mathrm{Si}$ atoms to see if there is local magnetic effect. We chose site 0 as the research object, as shown in Figure 1. The doping concentration of Co-doped $4 \mathrm{H}-\mathrm{SiC}$ is 2.78 at.\%. As a result, the total magnetic moment of Co-doped $4 \mathrm{H}-\mathrm{SiC}$ system is $3.02 \mu_{B}$ and the Co atom plays a major role. Here, a Co atom provides a magnetic moment of $2.14 \mu_{B}$. Next, we calculated the total DOS and partial DOS of the Co-doped $4 \mathrm{H}-\mathrm{SiC}$ system, as shown in Figure 3. We can see from Figure 3 a that the total DOS are asymmetrical, which may be the origin of the magnetic properties. Further, we have given the spin-related partial DOS of $\mathrm{Co}$, $\mathrm{Si}$ and $\mathrm{C}$ atoms of $\mathrm{Si}_{35} \mathrm{CoC}_{36}$ listed in Figure $3 \mathrm{~b}-\mathrm{d}$. The results show that the spin up and spin down of the total DOS are asymmetric, indicating that the Co-doped $4 \mathrm{H}-\mathrm{SiC}$ system has magnetic properties. It is found that the Co:3d state has a significant contribution near the Fermi level. For the Co-doped $4 \mathrm{H}-\mathrm{SiC}$ systems, as shown in Figure $3 \mathrm{~b}-\mathrm{d}$, the Co:3d states and the C:2p states have strong hybridization near the Fermi level. It is worth noting that majority and minority spin have significant asymmetry in total DOS, which comes from the Co:3d states. This indicates that the Co:3d states have a large effect on the induction of magnetic moment. The change of the energy gap with different doping atoms can be explained by partial DOS analysis.

\section{2. (Cr, Co)-codoped $4 \mathrm{H}-\mathrm{SiC}$}

In the following calculations, we considered the magnetic properties of $(\mathrm{Cr}, \mathrm{Co})$-codoped $4 \mathrm{H}-\mathrm{SiC}$. The ferromagnetic stability of $\mathrm{Cr}$ and $\mathrm{Co}$ atoms in $(\mathrm{Cr}, \mathrm{Co})$-codoped $4 \mathrm{H}-\mathrm{SiC}$ was investigated by replacing $\mathrm{Si}$ at different positions with $\mathrm{Co}$, and the relationship between $\mathrm{Cr}$ and $\mathrm{Co}$ sites and magnetic properties was found. As shown in Figure 1, we calculated 12 configurations of $(\mathrm{Cr}$, $\mathrm{Co})$-codoped $4 \mathrm{H}-\mathrm{SiC}$. The 12 configurations of the lattice parameters, $\mathrm{Cr}$-Co distance $(d(\mathrm{Cr}-\mathrm{Co}))$ before 
(Non-spin-polarization, NSP) and after (Spin-polarization, SP) relaxation, magnetization energy $\left(\Delta E_{F M}\right)$ and the magnetic moment $(M)$ of total, $\mathrm{Cr}$ and $\mathrm{Co}$ atoms are summarized in Table 1 . The magnetization energy $\left(\Delta E_{F M}=E_{F M}-E_{A F M}\right)$ is used to evaluate the relative stability of ferromagnetism (FM) and anti-ferromagnetism (AFM) states, where $E_{F M}$ and $E_{A F M}$ are the total energies for ferromagnetism and anti-ferromagnetism ordering, respectively. If $\Delta E_{F M}$ is negative, it means that the system was ferromagnetic, and if $\Delta E_{F M}$ is positive, it means that the system was anti-ferromagnetic.

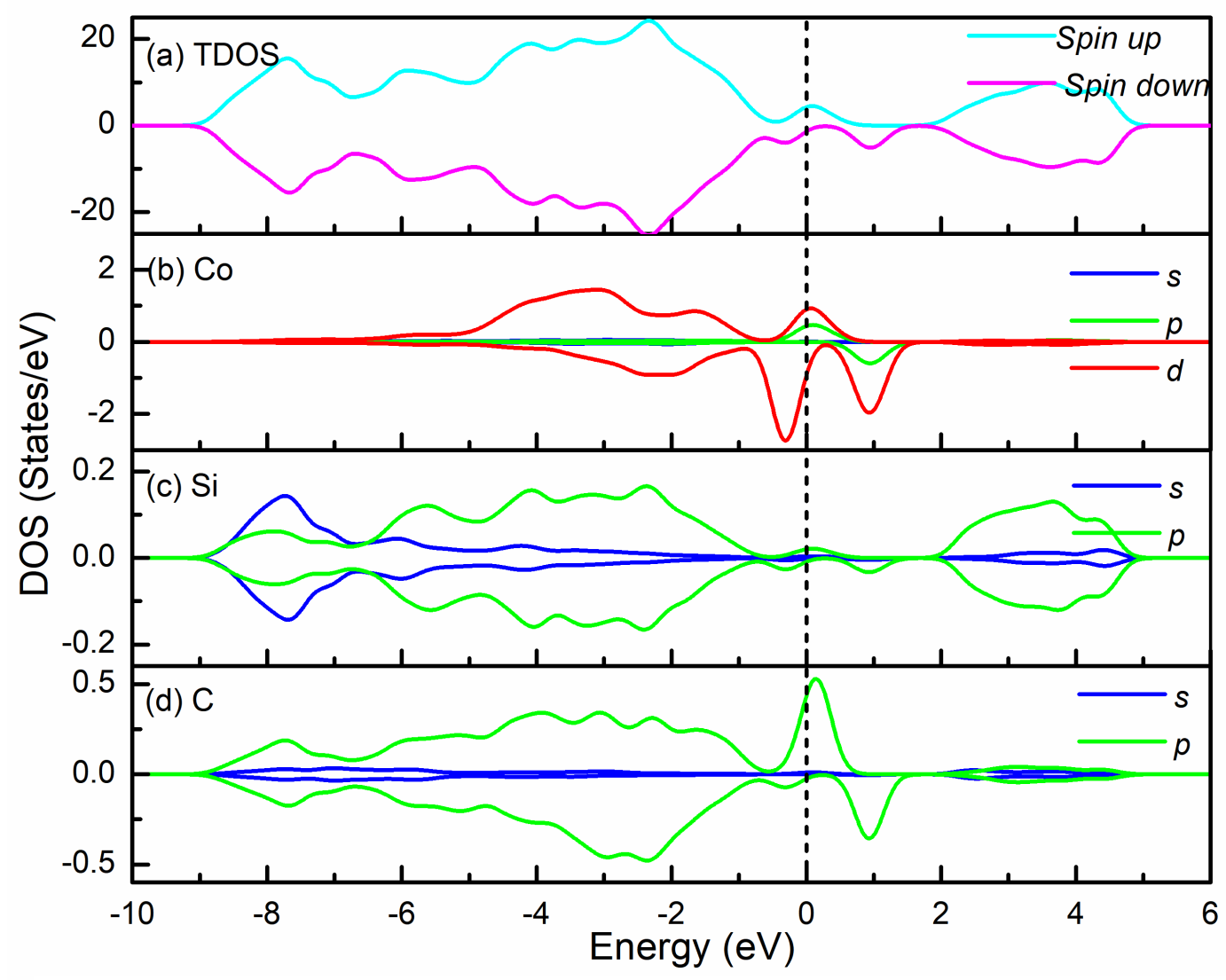

Figure 3. (a-d) The total and partial DOS of Co-doped $4 \mathrm{H}-\mathrm{SiC}$. The Fermi level is set to $0 \mathrm{eV}$.

By optimizing the spacing of $\mathrm{Cr}$ and $\mathrm{Co}$ atoms before and after optimization, it is found that the variation of the spacing between $\mathrm{Cr}$ and $\mathrm{Co}$ atoms is about $0.05 \AA$, which show that the geometry of $(\mathrm{Cr}, \mathrm{Co})$-codoped $4 \mathrm{H}-\mathrm{SiC}$ does not change much, indicating the rationality of the cell. The results show that the doped super-cells established by us are correct and the calculated structural data is reliable. The results also show that the calculation results are very accurate for the total DOS and partial DOS analysis. Our results show that magnetic atoms tend to be ferromagnetic coupled, as shown in Table 1 , the most stable configuration of ferromagnetism is the $(0,10)$ configuration with $\Delta E_{F M}$ $-244.3 \mathrm{meV}$. In the experiment, the influence of the structure for the company and magnetic doping $\mathrm{SiC}$ film was studied by Sun et al. [39], and they found that when the annealing temperature rose to $1200{ }^{\circ} \mathrm{C}$, the doping atom Co formed the compound complete CoSi, and the magnetic film results showed that all films exhibit intrinsic ferromagnetism at $300 \mathrm{~K}$. In order to evaluate the intensity of FM magnetic coupling, the $T_{C}$ is roughly estimated by the mean-field approximation method of total energy difference $\Delta E_{F M}=E_{F M}-E_{A F M}$, and calculated by the following formula [40,41]:

$$
T_{C}=2 \Delta E_{F M} / 3 k_{B} x
$$

where the $k_{B}$ is the Boltzmann constant and $x$ is the sum of doping atoms $(x=2)$. By using the Equation (1), we estimated $T_{C}$ of about $470.8 \mathrm{~K}$ for the $(\mathrm{Cr}, \mathrm{Co})$-codoped $4 \mathrm{H}-\mathrm{SiC}$ system. It can 
be expected that above room temperature ferromagnetism can be obtained for ( $\mathrm{Cr}$, $\mathrm{Co}$ )-codoped $4 \mathrm{H}-\mathrm{SiC}$-based DMSs. In the next calculation, we chose $(\mathrm{Cr}, \mathrm{Co})$-codoped $4 \mathrm{H}-\mathrm{SiC}$ the most stable ferromagnetic configuration $(0,10)$ as the research object, as shown in Figure 1 . The total magnetic moment of $(\mathrm{Cr}, \mathrm{Co})$-codoped $4 \mathrm{H}-\mathrm{SiC}$ system in $(0,10)$ configuration is $6.02 \mu_{B}$, which is on account of Co impurity at Si site. The $\mathrm{Cr}$ and Co atoms play an important role in the generation of the total magnetic moment, and the $\mathrm{Cr}$ and $\mathrm{Co}$ atoms contribute $2.16 \mu_{B}$ and $3.00 \mu_{B}$ to the moment. To further investigate the magnetic origin, we calculated the total DOS and partial DOS for $(0,10)$ configuration of (Cr, Co)-codoped 4H-SiC system, as shown in Figure 4. The total integer magnetic moment is consistent with the semi-metallic property shown by the total DOS (see Figure 4), which is consistent with the total magnetic moment obtained from the spin-resolved of total DOS. The (Cr, Co)-codoped $4 \mathrm{H}-\mathrm{SiC}$ can be ferromagnetic through some mechanism based on hybridization between local Cr:3d, Co: $3 d$ and $C: 2 p$ states.

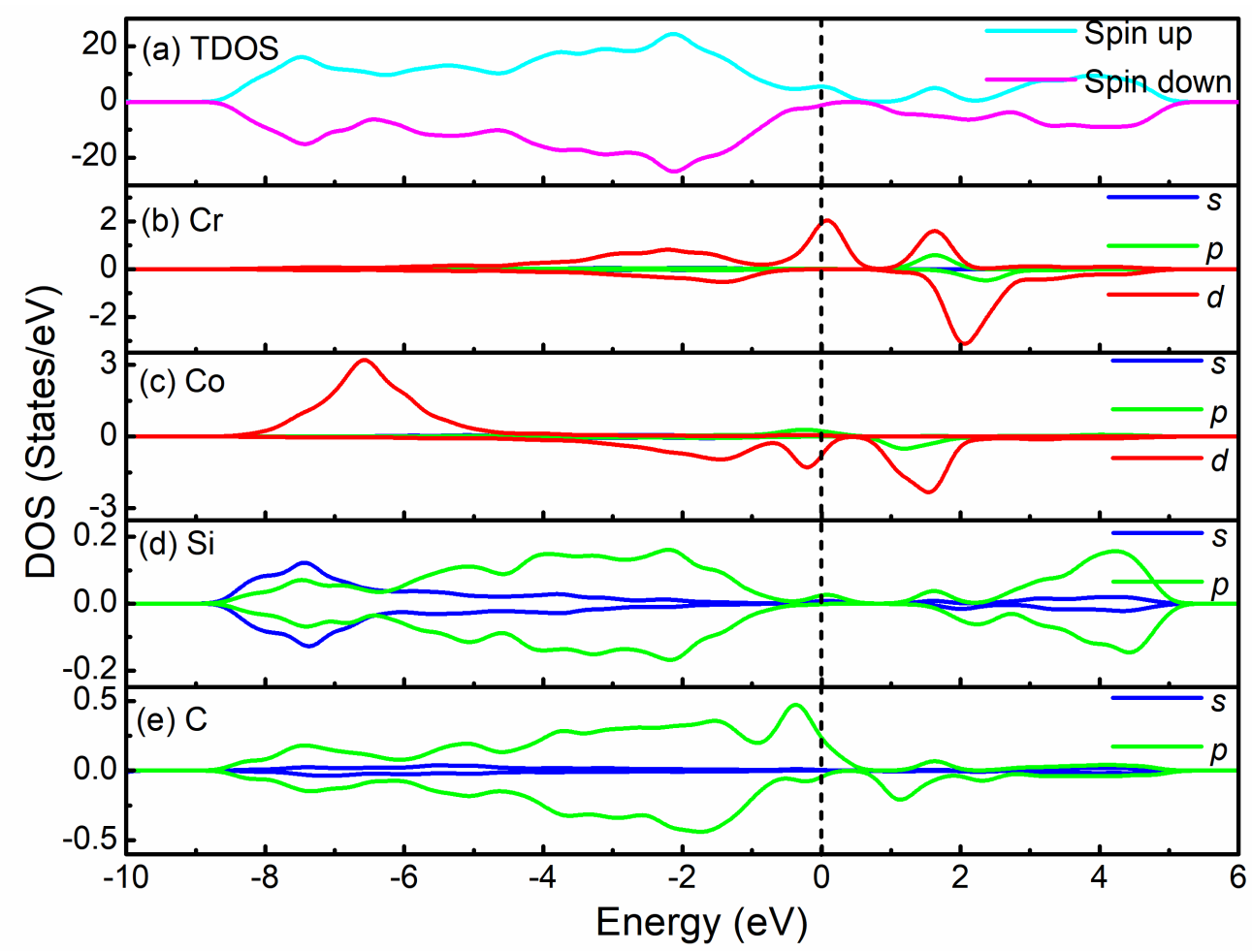

Figure 4. (a-e) Total and partial density of states of $(0,10)$ configuration $(\mathrm{Cr}, \mathrm{Co})$-codoped $4 \mathrm{H}-\mathrm{SiC}$. The Fermi level is set to $0 \mathrm{eV}$.

In order to consider the effect of adding $U$ on the system, we further considered the effect of adding $U$ on the system magnetism. As we expected, when we consider the calculation results of all ferromagnetic configurations with $U$, we find that the most stable ferromagnetic state $(0,10)$ configuration changes little with $\Delta E_{F M}-222.3 \mathrm{meV}$. The spin population of atoms can also be visually displayed by the way of atom coloring. To understand the magnetic property, the spin density of states is calculated to further investigate the interaction of $(0,10)$ configuration of $(\mathrm{Cr}, \mathrm{Co})$ co-doped $4 \mathrm{H}-\mathrm{SiC}$, which is shown in Figure 5 . The value is set to $0.05 \mathrm{e} /{ }^{3}$. It turns out that the spin-up moments (blue isosurface) locate mainly on $\mathrm{TM}(\mathrm{TM}=\mathrm{Cr}, \mathrm{Co})$ atoms, while the spin-down moments (yellow isosurface) locate mainly on the surrounding $\mathrm{C}$ atoms or even not display. The total magnetic moment arises mainly from $\mathrm{TM}(\mathrm{TM}=\mathrm{Cr}, \mathrm{Co})$ atoms, while the contribution of the three nearest-neighbor $\mathrm{C}$ atoms with a shorter TM-C bonds. For ( $\mathrm{Cr}, \mathrm{Co})$-codoped $4 \mathrm{H}-\mathrm{SiC}$ system, the magnetic moment is mainly dominated by $\mathrm{Cr}: 3 d$ states and $\mathrm{Co}: 3 d$ states. The hybridization between $\mathrm{C}: 2 p, \mathrm{Cr}: 3 d$ and Co:3d states is observed in Figure 5. It is obvious from Figure 5 that the coupling between C:2p, Cr:3d and $\mathrm{Co}: 3 d$ states is the main reason for the strong ferromagnetism of $(\mathrm{Cr}, \mathrm{Co})$-codoped $4 \mathrm{H}-\mathrm{SiC}$ system. 
Table 1. Calculation results of 12 configurations for $(\mathrm{Cr}, \mathrm{Co})$-codoped $4 \mathrm{H}-\mathrm{SiC}$, lattice parameters, $\mathrm{Cr}-\mathrm{Co}$ distance $(d(\mathrm{Cr}-\mathrm{Co}))$ before $(\mathrm{NSP})$ and after $(\mathrm{SP})$ relaxation, magnetization energy $\left(\Delta E_{F M}\right)$ and the magnetic moment $(M)$ of total, $\mathrm{Cr}$ and $\mathrm{Co}$ atoms, respectively.

\begin{tabular}{|c|c|c|c|c|c|c|c|c|c|c|}
\hline $\begin{array}{c}\text { Configuration } \\
(a, b)\end{array}$ & $a$ & $b$ & $c$ & $\begin{array}{l}d(\mathrm{Cr}-\mathrm{Co}) \\
\text { (NSP) }\end{array}$ & $\begin{array}{l}(\AA ̊) \\
\text { (SP) }\end{array}$ & $\begin{array}{l}\Delta E_{F M} \\
(\mathrm{meV})\end{array}$ & Total & $\begin{array}{l}M\left(\mu_{B}\right) \\
\mathrm{Cr}\end{array}$ & Co & Coupling \\
\hline$(0,1)$ & 9.28 & 9.28 & 10.14 & 3.082 & 3.028 & -223.3 & 5.98 & 2.16 & 2.98 & FM \\
\hline$(0,2)$ & 9.27 & 9.28 & 10.12 & 5.338 & 5.355 & 614.0 & 6.04 & 2.35 & 2.61 & AFM \\
\hline$(0,3)$ & 9.27 & 9.27 & 10.12 & 6.163 & 6.241 & 668.6 & 6.01 & 2.39 & 2.59 & AFM \\
\hline$(0,4)$ & 9.27 & 9.28 & 10.12 & 8.153 & 8.204 & 615.4 & 6.02 & 2.41 & 2.58 & AFM \\
\hline$(0,5)$ & 9.28 & 9.28 & 10.12 & 4.360 & 4.363 & 236.2 & 5.99 & 2.36 & 2.61 & AFM \\
\hline$(0,6)$ & 9.28 & 9.27 & 10.13 & 5.339 & 5.348 & 258.9 & 6.03 & 2.34 & 2.62 & AFM \\
\hline$(0,7)$ & 9.29 & 9.29 & 10.14 & 6.892 & 6.959 & -84.0 & 6.03 & 2.17 & 2.99 & FM \\
\hline$(0,8)$ & 9.28 & 9.29 & 10.13 & 8.155 & 8.205 & -179.2 & 5.96 & 2.13 & 2.97 & FM \\
\hline$(0,9)$ & 9.29 & 9.28 & 10.14 & 5.344 & 5.346 & -204.9 & 6.03 & 2.12 & 3.01 & FM \\
\hline$(0,10)$ & 9.28 & 9.29 & 10.13 & 6.169 & 6.198 & -244.3 & 6.02 & 2.16 & 3.00 & FM \\
\hline$(0,11)$ & 9.30 & 9.29 & 10.14 & 6.896 & 6.927 & 9.6 & 6.01 & 2.16 & 3.00 & AFM \\
\hline$(0,12)$ & 9.28 & 9.29 & 10.13 & 8.158 & 8.189 & -227.7 & 6.01 & 2.13 & 3.00 & FM \\
\hline
\end{tabular}




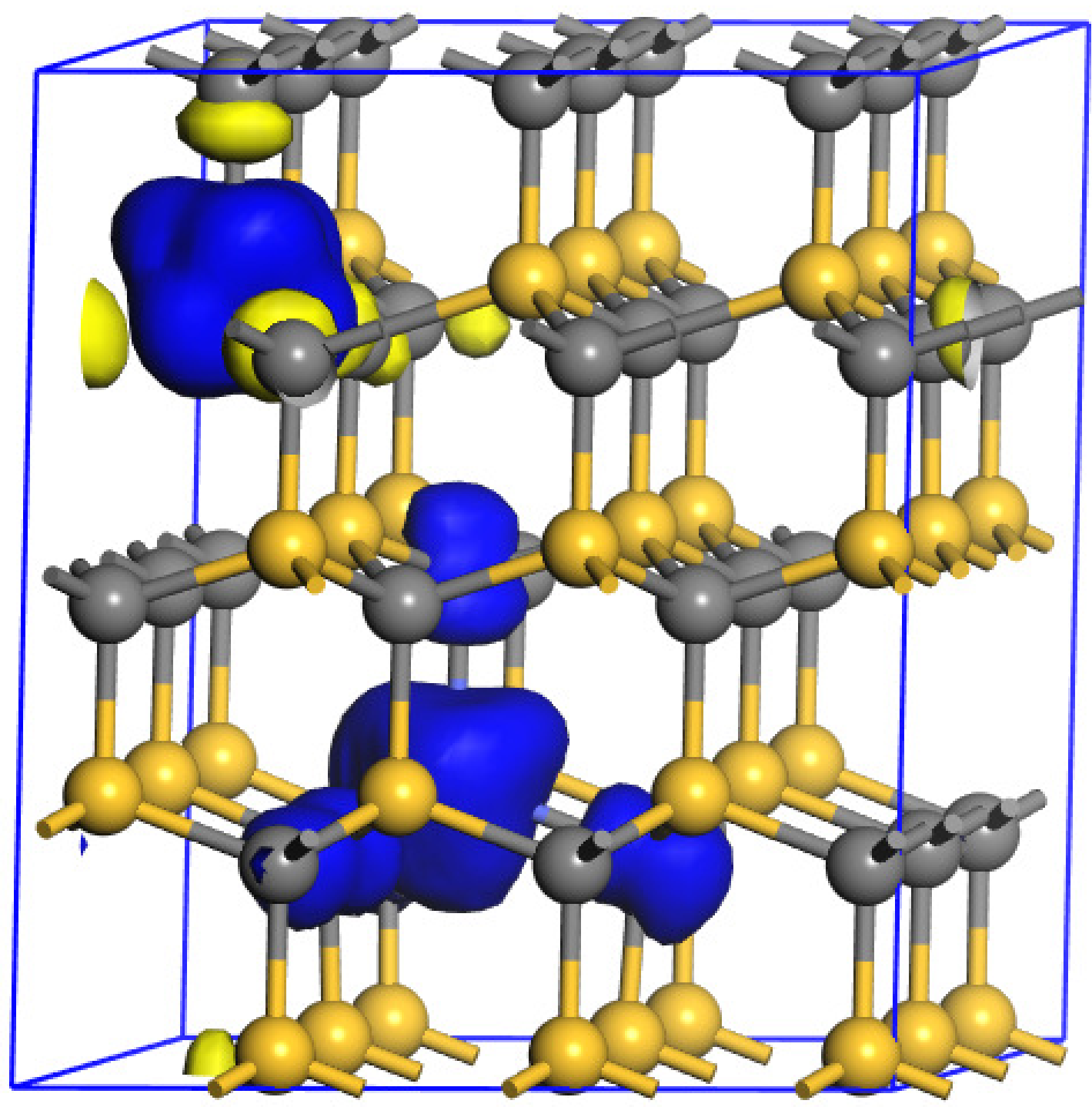

Figure 5. Spin density distribution of ( $\mathrm{Cr}, \mathrm{Co})$-codoped $4 \mathrm{H}-\mathrm{SiC}$ in ferromagnetism coupling. The blue and cyan yellow display positive and negative spin charge density. The isovalue is set to $0.05 \mathrm{e} /{ }^{3}$.

\section{3. (Cr, Co, $\left.V_{S i}\right)$-codoped $4 \mathrm{H}-\mathrm{SiC}$}

Studies on silicon vacancy and carbon vacancy have been reported in previous literature [42], and we define $V_{S i}$ and $V_{C}$ indicate the formation of silicon vacancy and carbon vacancy. From their computational results, it is found that the formation energy of $V_{S i}$ is slightly less than that of $V_{C}$, which makes it easier to remove a $\mathrm{Si}$ atom than $\mathrm{C}$ atom in $4 \mathrm{H}-\mathrm{SiC}$ system, and there's a pattern in other $\mathrm{SiC}$ systems [43,44]. So it is interesting to investigate the impact of $V_{S i}$ on the electronic structures and magnetic properties. In the following calculation, we calculated $\left(\mathrm{Cr}, \mathrm{Co}, V_{S i}\right)$-codoped $4 \mathrm{H}-\mathrm{SiC}$ system based on the $(0,10)$ configuration, as seen in Figure 1 . As a result, $\Delta E_{F M}$ of $\left(\mathrm{Cr}, \mathrm{Co}, V_{S i}\right)$-codoped $4 \mathrm{H}-\mathrm{SiC}$ system is $-58.7 \mathrm{meV}$, which indicates that the magnetism of the system is weakened after the introduction of $V_{S i}$, while the whole system shows ferromagnetism. 
In order to further understand the cause of magnetic changes, here taking the change of the magnetism of $(0,10)$ configuration for $\left(\mathrm{Cr}, \mathrm{Co}, V_{S i}\right)$-codoped $4 \mathrm{H}-\mathrm{SiC}$ system as an example. We also investigated the total and partial DOS of $\left(\mathrm{Cr}, \mathrm{Co}, V_{S i}\right)$-codoped $4 \mathrm{H}-\mathrm{SiC}$ for comparison. As seen in Figure 6, Figure $6 \mathrm{a}$ is the total DOS of $\left(\mathrm{Cr}, \mathrm{Co}, V_{S i}\right)$-codoped $4 \mathrm{H}-\mathrm{SiC}$, and Figure $6 \mathrm{~b}-\mathrm{e}$ are partial DOS of $\mathrm{Cr}, \mathrm{Co}, \mathrm{Si}$ and $\mathrm{C}$ atoms. The lower impurity state near Fermi level mainly comes from hybridization of $\mathrm{Cr}: 3 d$ and $\mathrm{C}: 2 p$ states with some contributions of $\mathrm{Co}: 3 d$ and $\mathrm{C}: 2 p$ states. To further clarify the characteristic of the magnetism in $\left(\mathrm{Cr}, \mathrm{Co}, V_{S i}\right)$-codoped $4 \mathrm{H}-\mathrm{SiC}$, the visualized spin density distributions are displayed in Figure 7 , with a $0.05 \mathrm{e} /{ }^{3}$ iso-surface. The results show that the ferromagnetic coupling of $\left(\mathrm{Cr}, \mathrm{Co}, V_{S i}\right)$-codoped $4 \mathrm{H}-\mathrm{SiC}$ system is obviously weaker than that without $V_{S i}$. Our results are consistent with those of Lin et al. [42] In addition, Lin et al. also studied the effect of the presence of carbon vacancies on the ferromagnetism of $4 \mathrm{H}-\mathrm{SiC}$ system, and they found that the ferromagnetism of the system would be enhanced due to the presence of carbon vacancies. Therefore, silicon vacancy should be avoided as much as possible in the actual production.

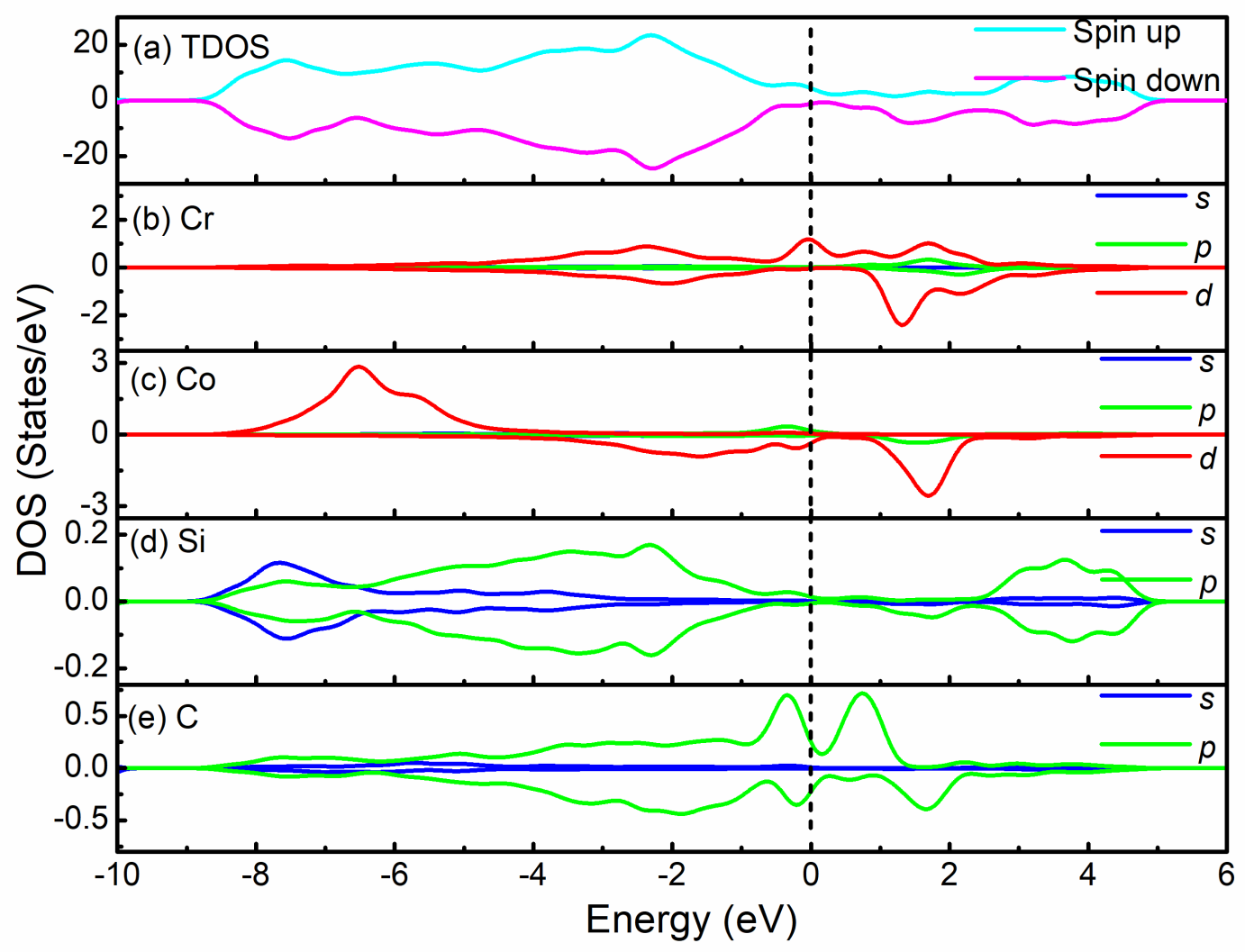

Figure 6. (a-e) Total and partial density of states of $(0,10)$ configuration $\left(\mathrm{Cr}, \mathrm{Co}, V_{S i}\right)$-codoped $4 \mathrm{H}-\mathrm{SiC}$. The Fermi level is set to $0 \mathrm{eV}$.

In the end, we make a conclusion that $V_{S i}$ doped $4 \mathrm{H}-\mathrm{SiC}$ is not a suitable candidate for exploring the origin of magnetism due to the inappropriate $\Delta E_{F M}$. Therefore, the introduction of similar defects should be avoided in future scientific research work. 


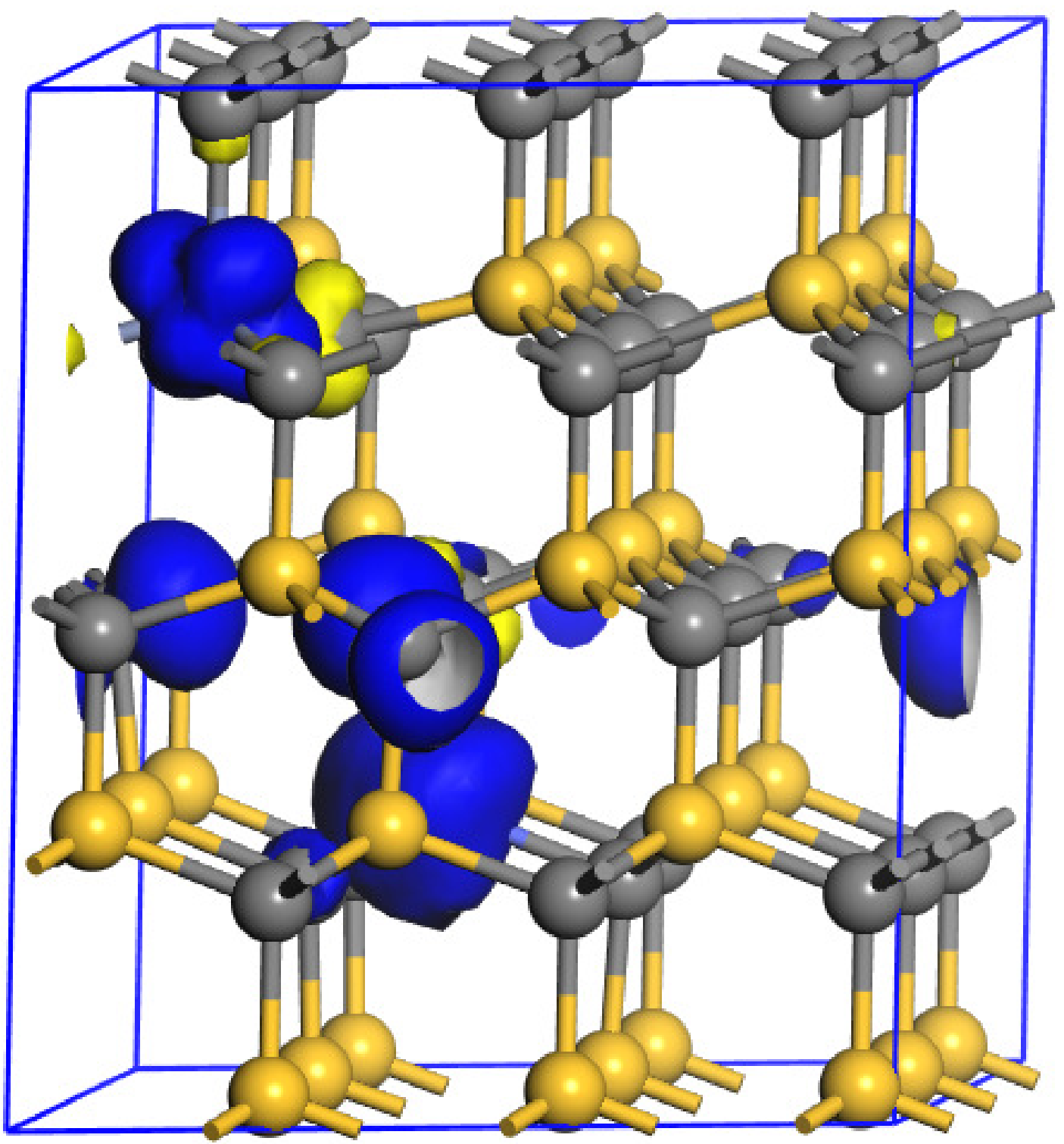

Figure 7. Spin density distribution of $\left(\mathrm{Cr}, \mathrm{Co}, \mathrm{V}_{S i}\right)$-codoped $4 \mathrm{H}-\mathrm{SiC}$ in ferromagnetism coupling. The blue and cyan yellow display positive and negative spin charge density. The isovalue is set to $0.05 \mathrm{e} /{ }^{3}$.

\section{Conclusions}

In a word, we have done first-principles calculations to study structure, electron and magnetism of $\mathrm{Cr}$ - and Co-mondoped, $(\mathrm{Cr}, \mathrm{Co})$ - and $\left(\mathrm{Cr}, \mathrm{Co}, V_{S i}\right)$-codoped $4 \mathrm{H}-\mathrm{SiC}$ system with different configurations. This work demonstrates the magnetic behavior of $4 \mathrm{H}-\mathrm{SiC}$ with the help of total spin-polarized energies, magnetic moment, total DOS and partial DOS. In Cr-doped case, the magnetism with maximum magnetic moment of $3.03 \mu_{B}$ on account of $\mathrm{Cr}$ impurity at Si site, and the doping $\mathrm{Cr}$ contributes $2.79 \mu_{B}$ to the moment. In the Co-doped case, the total magnetic moment of the Co-doped $4 \mathrm{H}-\mathrm{SiC}$ system is $3.02 \mu_{B}$, and the Co atom contributes $2.14 \mu_{B}$. The ferromagnetism of the most stable ferromagnetism configuration changes little between GGA and GGA+U. The results show that $(\mathrm{Cr}, \mathrm{Co})$-codoped $4 \mathrm{H}-\mathrm{SiC}$ is semi-metallic properties. Our calculation results show that the magnetic moments are large and reach up to $6.02 \mu_{B}$ with $\Delta E_{F M}-244.3 \mathrm{meV}$ in (Cr, Co)-codoped $4 \mathrm{H}-\mathrm{SiC}$ systems, and we estimated $T_{C}$ of about $470.8 \mathrm{~K}$ for the $(\mathrm{Cr}, \mathrm{Co})$-codoped $4 \mathrm{H}-\mathrm{SiC}$ system. Therefore, the $(\mathrm{Cr}, \mathrm{Co})$-codoped $4 \mathrm{H}-\mathrm{SiC}$ is a very promising magnetic material for spintronic devices. 
The research results also show that the introduction of silicon-vacancy weakens the magnetism of the system, while the introduction of carbon vacancy enhances the magnetism of the system. Our calculation results have a guiding effect on the application of a dilute magnetic semiconductor. In all, ( $\mathrm{Cr}, \mathrm{Co}$ )-codoped $4 \mathrm{H}-\mathrm{SiC}$ may be a good candidate in the electronic and magnetic fields.

Author Contributions: Data curation, M.Z.; Methodology, L.L.; Validation, X.L.; Formal analysis, J.H.; Resources, H.L.T.; Data curation, M.Z.; Writing-original draft preparation, J.H.; Writingreview and editing, L.L.; Visualization, H.T.; Supervision, M.Z., X.L.; Project administration, L.L.; Funding acquisition, L.L., H.T.; All authors have read and agreed to the published version of the manuscript.

Funding: This work was supported by the Key Projects of NSFC-Henan Joint Fund (U1704255), the National Natural Science Foundation of China (11804081), the Key Research Project for the Universities of Henan Province (19A140009, 19B430003, 20A430016), the National Natural Science Foundation of China (Grant Nos. 21603109), the Henan Joint Fund of the National Natural Science Foundation of China (Grant No. U1404216), the One Thousand Talent Plan of Shaanxi Province, Natural Science Foundation of Liaoning and Doctor Start-up Fund of Liaoning under Grant (20170520155). China Postdoctoral Science Foundation (2019M652425).

Acknowledgments: Computational resources have been provided by the Henan Polytechnic University high-performance grid computing platform.

Conflicts of Interest: The authors declare no conflicts of interest.

\section{References}

1. Kacman, P. Spin interactions in diluted magnetic semiconductors and magnetic semiconductor structures. Semicond. Sci. Technol. 2001, 16, R25-R39. [CrossRef]

2. Sato, K.; Bergqvist, L.; Kudrnovsk, J. First-principles theory of dilute magnetic semiconductors. Rev. Mod. Phys. 2010, 82, 1633-1690. [CrossRef]

3. Masrour, R.; Hlil, E.K.; Hamedoun, M.; Benyoussef, A. Electronic and magnetic structures of FeSn compound investigated by first principle, mean field and series expansions calculations. Phys. Stat. Mech. Its Appl. 2014, 414, 249-253. [CrossRef]

4. Akinaga, H.; Ohno, H. Semiconductor spintronics. Phys. Status Solidi 2012, 251, 1651. [CrossRef]

5. Masrour, R.; Hlil, E.K.; Hamedoun, M.; Benyoussef, A. Antiferromagnetic spintronics of $\mathrm{Mn}_{2} \mathrm{Au}$ : An experiment, first principle, mean field and series expansions calculations study. J. Magn. Magn. Mater. 2015, 393, 600-603. [CrossRef]

6. Lin, L.; Huang, J.T.; Yu, W.Y.; Zhu, L.H.; Wang, P.T.; Xu, Y.H.; Tao, H.L.; Zhang, Z.Y. First principles study of the electronic and magnetic properties of (Co,Ga) co-doped $\mathrm{LiNbO}_{3}$. J. Appl. Phys. 2019, 125, 073901. [CrossRef]

7. Shinde, S.R.; Ogale, S.B.; Higgins, J.S.; Zheng, H.; Millis, A.J.; Kulkarni, V.N.; Ramesh, R.; Greene, R.L.; Venkatesan, T. Co-occurrence of Superparamagnetism and Anomalous Hall Effect in Highly Reduced Cobalt-Doped RutileTiO 2 . Phys. Rev. Lett. 2004, 92, 166601. [CrossRef]

8. Tietze, T.; Gacic, M.; Schütz, G.; Jakob, G.; Brück, S.; Goering, E. XMCD studies on Co and Li doped ZnO magnetic semiconductors. New J. Phys. 2018, 10, 055009. [CrossRef]

9. Luo, M.; Yin, H.H.; Shen, Y.H. Magnetic Properties in Nonmagnetic Metal Atom Adsorption on SiC Monolayer: First-Principles Study. J. Supercond. Nov. Magn. 2017, 31, 1-6. [CrossRef]

10. Jiang, Z.; Xu, X.; Wu, H.; Zhang, F.; Jin, Z. Ab initio calculation of SiC polytypes. Solid State Commun. 2002, 123, 263-266. [CrossRef]

11. Kim, K.J.; Kim, Y.W. Fe doping and magnetic properties of zincblende SiC ceramics. J. Eur. Ceram. Soc. 2012, 32, 1149-1155. [CrossRef]

12. Huang, Y.; Jiang, D.; Zhang, H.; Cheng, Z.; Huang, Z. Ferromagnetism of Al-doped 6H-SiC and theoretical calculation. Acta Phys. Sin. 2017, 66, 307-313.

13. Zhang, C. Density-functional theory study of long-range ferromagnetic properties in Mg-doped SiC. Solid State Commun. 2010, 150, 2310-2313. [CrossRef]

14. Weber, J.R.; Koehl, W.F.; Varley, J.B.; Janotti, A.; Buckley, B.B.; van de Walle, C.G.; Awschalom, D.D. Defects in $\mathrm{SiC}$ for quantum computing. J. Appl. Phys. 2011, 109, 102417. [CrossRef] 
15. Christle, D.J.; Falk, A.L.; Andrich, P.; Klimov, P.V.; Hassan, J.U.; Son, N.T.; Janzen, E.; Ohshima, T.; Awschaloml, D.D. Isolated electron spins in silicon carbide with millisecond coherence times. Nat. Mater. 2015, 14, 160-163. [CrossRef]

16. Widmann, M.; Lee, S.Y.; Rendler, T.; Son, N.T.; Fedder, H.; Paik, S.; Yang, L.P.; Zhao, N.; Yang, S.; Booker, I.; et al. Coherent control of single spins in silicon carbide at room temperature. Nat. Mater. 2015, 14, 164-168. [CrossRef]

17. Lin, X.; Pan, F. The Electronic Structures and Magnetism in Al Doped 4H-SiC: The First-Principles Calculation. J. Alloys Compd. 2016, 687, 227-231. [CrossRef]

18. Zhang, X.; Han, J.C.; Zhou, J.G.; Xin, C.; Zhang, Z.H.; Song, B. Ferromagnetism in homogeneous (Al,Co)-codoped 4H-silicon carbides. J. Magn. Magn. Mater. 2014, 363, 34-42. [CrossRef]

19. Yu, L.; Jin, H.; Liu, D.; Dai, Y.; Guo, M.; Huang, B.; Zhang, Z. Investigation of ferromagnetism in Al-doped $4 \mathrm{H}-\mathrm{SiC}$ by density functional theory. Chem. Phys. Lett. 2010, 496, 276-279. [CrossRef]

20. Song, B.; Bao, H.Q.; Li, H.; Lei, M.; Jian, J.K.; Han, J.C.; Zhang, X.H.; Meng, S.H.; Wang, W.Y.; Chen, X.L. Magnetic properties of Mn-doped 6H-SiC. Appl. Phys. Lett. 2009, 94, 102508. [CrossRef]

21. Wang, W.H.; Takano, F.; Ofuchi, H.; Akinaga, H. Magnetic properties of transparent SiC:Mn films synthesized on SiC substrates. J. Magn. Magn. Mater. 2007, 310, 2141-2143. [CrossRef]

22. Huang, Z.; Chen, Q.W. Magnetic properties of Cr-doped 6H-SiC single crystals. J. Magn. Magn. Mater. 2007, 313, 111-114. [CrossRef]

23. Ma, P.T.; Lei, T.M.; Zhang, Y.M.; Liu, J.J.; Zhang, Z.Y. First-Principle Study on Magnetic Properties of TM-Doped 6H-SiC. Adv. Mater. Res. 2013, 709, 197-200. [CrossRef]

24. Azri, A.M.; Elzain, M.; Bouziane, K.; Cherif, S.M.; Declemy, A.; Thome, L. Model for Mn in 6H-SiC from first-principle studies. J. Appl. Phys. 2013, 113, 17C305. [CrossRef]

25. Bouziane, K.; Mamor, M.; Elzain, M. Defects and magnetic properties in Mn-implanted 3C-SiC epilayer on Si(100): Experiments and first-principles calculations. Phys. Rev. B. 2008, 78, 195305. [CrossRef]

26. Luo, M.; Shen, Y.H. Magnetic Properties of SiC Monolayer with Different Nonmagnetic Metal Dopants. J. Supercond. Nov. Magn. 2018, 31, 3277-3282. [CrossRef]

27. Pacheco, J.M.; Gueorguiev, G.K.; Martins, J.L. First-principles study of the possibility of condensed phases of endohedral silicon cage clusters. Phys. Rev. B. 2002, 66, 334011-334013. [CrossRef]

28. Oliveira, M.I.A.; Rivelino, R.; Mota, F.d.; Gueorguiev, G.K. Optical Properties and Quasiparticle Band Gaps of Transition-Metal Atoms Encapsulated by Silicon Cages. J. Phys. Chem. C 2014, 118, 5501-5509. [CrossRef]

29. Segall, M.D.; Lindan, P.J.D.; Probert, M.J.; Pickard, C.J.; Hasnip, P.J.; Clark, S.J.; Payne, M.C. First-principles simulation: ideas, illustrations and the CASTEP code. J. Phys. Condens. Matter 2002, 14, 2717-2744. [CrossRef]

30. Perdew, J.P.; Burke, K.; Ernzerhof, M. Generalized Gradient Approximation Made Simple. Phys. Rev. Lett. 1996, 77, 3865-3868. [CrossRef]

31. Jones, R.O.; Gunnarsson, O. The density functional formalism, its applications and prospects. Rev. Mod. Phys. 1989, 61, 689-746. [CrossRef]

32. Perdew, J.P.; Wang, Y. Accurate and simple analytic representation of the electron-gas correlation energy. Phys. Rev. B Condensed Matter 1992, 45, 13244-13249. [CrossRef] [PubMed]

33. Marsman, M.; Paier, J.; Stroppa, A.; Kresse, G. Hybrid functionals applied to extended systems. J. Phy. Condens. Matter 2008, 20, 064201. [CrossRef] [PubMed]

34. Benouis, M.; Azzaz, Y.; Ameri, M.; Arbouche, O.; Bennadji, A.; Bensaid, D.; Al-Douri, Y. Electronic and Magnetic Properties of $\mathrm{Cr}_{2} \mathrm{GeC}$ with GGA+U Approximation. J. Supercond. Nov. Magn. 2016, 29, 1267-1272. [CrossRef]

35. Rozsalyi, E.; Verger, L.; Cabaret, D.; Juhin, A. DFT+U calculation of the Cr K pre-edge structures in $\mathrm{ZnCr}_{2} \mathrm{O}_{4}$. J. Phys. Conf. Ser. 2016, 712, 012011. [CrossRef]

36. Lin, L.; Huang, J.T.; Yu, W.Y.; Tao, H.L. Electronic structures and magnetic properties of (Ni,Al) co-doped 4H-SiC: A first-principles study. Comput. Mater. Sci. 2018, 155, 169-174. [CrossRef]

37. Zhang, C.; Yan, S. First-principles study on ferromagnetism in Mg-doped $\mathrm{SnO}_{2}$. Appl. Phys. Lett. 2009, 95, 232108. [CrossRef]

38. Wang, H.; Yan, Y.; Du, X.; Liu, X.; Li, K.; Jin, H. Origin of ferromagnetism in Ni-doped $\mathrm{SnO}_{2}$ : First-principles calculation. J. Appl. Phys. 2010, 107, 103923. [CrossRef] 
39. Sun, X.K.; Liu, J.W.; Liu, K.L.; Wang, S.H.; Zhao, L.L.; Qin, W.; Wang, G.L.; Meng, M.; Li, J.T.; Dong, X. Effect of temperature on the structure and magnetic properties of Co doped SiC films. Superlattices Microstruct. 2017, 107, 144-149. [CrossRef]

40. Sena, N.; Dussan, A.; Mesa, F.; Castano, E. Electronic structure and magnetism of Mn-doped GaSb for spintronic applications: A DFT study. J. Appl. Phys. 2016, 120, 110. [CrossRef]

41. Kudrnovsky, J.; Turek, I.; Drchal, V.; Maca, F.; Weinberger, P. Exchange interactions in III-V and group-IV diluted magnetic semiconductors. Phys. Rev. B 2004, 69, 115208. [CrossRef]

42. Lin, L.; Yan, L.B.; Huang, J.T.; Tao, H.L.; Zhang, J.S.; Yu, W.Y.; Xu, Y.H. First-principles investigations of the effect of $\mathrm{V}$ and Fe dopants on the magnetic and optical properties of $4 \mathrm{H}-\mathrm{SiC}$. Thin Solid Films 2020, 709, 138182. [CrossRef]

43. Zywietz, A.; Furthmüller, J.F.; Bechstedt, F. Vacancies in SiC: influence of Jahn-Teller distortions, spin effects, and crystal structure. Phys. Rev. B 1999, 59, 15166-15180. [CrossRef]

44. Salvador, M.; Perlado, J.M.; Mattoni, A.; Bernardini, F.; Colombo, L. Defect energetics beta-of-SiC using a new tight-binding molecular dynamics model. J. Nucl. Mater. 2004, 329-333, 1219-1222. [CrossRef]

(C) 2020 by the authors. Licensee MDPI, Basel, Switzerland. This article is an open access article distributed under the terms and conditions of the Creative Commons Attribution (CC BY) license (http://creativecommons.org/licenses/by/4.0/). 